\title{
Technology Spillovers between the U.S. and Japan
}

\author{
Jun-Hyung Ko \\ Graduate School of Economics, Hitotsubashi University \\ 2-1 Naka, Kunitachi, Tokyo, Japan \\ Tel: 81-42-580-8000Ｅ-mail: ed074002@g.hit-u.ac.jp
}

Received: August 2, 2011

doi:10.5539/ijef.v4n1p110
Accepted: September 13, $2011 \quad$ Published: January 1, 2012

URL: http://dx.doi.org/10.5539/ijef.v4n1p110

\begin{abstract}
What is the role of news shocks in the macroeconomic fluctuations in the Japanese economy, and what is the source of the news shocks? In this paper, we estimate a structural-vector-error-correction model (SVECM) and assess the relative role of news shocks on future total factor productivity (TFP) following the methodology of Beaudry and Portier (2005). We find that anticipated technology plays a substantial role in explaining the Japanese macroeconomic movements. To answer the second question, we investigate whether the TFP process in the U.S. can be the source of the Japanese news shocks. We identify U.S. TFP shocks in both surprise and anticipated forms and capture the international technology diffusion process. We find that the U.S. TFP shocks can explain a large part of the Japanese TFP process in the long run, and contributes considerably to the Japanese macroeconomic fluctuations.
\end{abstract}

Keywords: TFP spillover, News shock, Japanese Macroeconomy, Vector error correction model

\section{Introduction}

News shocks are a dark horse in the understanding of macroeconomic fluctuations. Beaudry and Portier $(2005,2006)$ insist that expected shocks are an important force behind business cycles. Using two identification schemes in the structural vector auto-regression (SVAR) model with co-integration vectors, they found that when the anticipated TFP shocks are informed to the market, forward looking variables such as stock prices react to the changes in expectations instantaneously, even before TFP actually changes. Beaudry and Portier (2005) found two almost co-linear shocks under two polar identifying assumptions for the U.S. and Japanese economies. They found that in the Japanese economy, like in the case of the U.S., news shocks are an important force, and the negative news shocks occurred at the beginning of the 1990s. Extending the work of Beaudry and Lucke (2009), Ko and Miyazawa (2010) explored several alternative identification schemes with more variables to assess the relative role of news shocks, and found the similar results.

In this paper, we investigated the role of news shocks based on SVECM, estimating news shocks in Japan based on the existing literature. The identification method used is an extension of Beaudry and Portier (2005), imposing both impact and long-run restrictions. Our benchmark variables are: measured TFP, an index of stock prices, and hours worked. Like Beaudry and Portier (2005) and Ko and Miyazawa (2010), we found that news shocks have been an important source of macroeconomic fluctuations in Japan over the last 40 years.

Second, we investigate the source of news shocks in Japan and the international spillover effect of TFP. Technological diffusion has been discussed in many previous works. For example, Parente and Prescott (1994) and Eaton and Kortum (1997) developed models of technological diffusion to analyze Japan's development miracle. Braun, Okada, and Sudo (2008) emphasized that an analysis of the factors leading to the growth in Japanese TFP indicates that the diffusion of business ideas from the U.S. has been an important ingredient in Japan's macroeconomic growth. Therefore, to explore the technology diffusion effect, we extend the SVAR model in two ways.

We include the measure of U.S. TFP in the benchmark model because it may influence Japan's future TFP. Thus, there are three candidates to increase Japan's future TFP in the four-variable system: surprise TFP shocks, news shocks, and U.S. TFP shocks. We set almost equal restrictions on the Japanese and U.S. TFP shocks, and hence, open the possibility that TFP in one country can influence it in the other. Our main findings are as follows. First, from the impulse responses, we observe technology diffusion between the two countries. The estimated news shocks in Japan start to increase Japanese TFP three years later. After the innovations in the Japanese stock market, U.S. TFP lags Japanese TFP, although the effect is statistically insignificant. On the other hand, U.S. TFP innovation significantly increases Japanese TFP four quarters later. In other words, the current innovation of U.S. TFP offers the 
indication that Japanese TFP will also increase in the near future. Second, the forecast error variance decomposition shows that a considerable fraction of the Japanese TFP in the medium and long run is explained by the U.S. TFP shocks. However, the contribution of both of surprise and news shocks in Japan is minor in explaining the variance of U.S. TFP. Third, the role of news shocks, which rarely have information of U.S. TFP in the four-variable system, becomes limited. Fourth, surprise TFP shocks in Japan can explain the short-run movement of Japanese TFP but have little effect on U.S. TFP.

Another extension is to investigate the role of news shocks on U.S. TFP. Inclusion of U.S. stock prices instead of Japanese stock prices enables us to identify the U.S. news shocks. We find U.S. stock price innovation starts to increase U.S. TFP around one year later, and then increase Japanese TFP around two years later. We find that news shocks on U.S. TFP play a major role in explaining the movements of Japanese TFP and macro activities in the long run.

The paper comprises three sections. Section 2 describes the identification procedure and the VAR. The benchmark results are presented in Section 3, while Section 4 conducts a robustness check. Section 5 concludes the paper.

\section{SVECM}

\subsection{Econometric Model}

This section presents our framework of the analysis: SVECM following Beaudry and Portier (2005), Beaudry and Lucke (2009), and Ko and Miyazawa (2010). We use both short and long-run restrictions, which enable us to identify news shocks and to link the technology diffusion processes and business cycle fluctuations. In this benchmark case, we identify the following three shocks: surprise TFP shocks, news shocks, and demand shocks. The following measures are used to work with a three-dimensional SVECM: measured TFP ( $t f p$ ), stock price indices $(s p)$, and hours worked $(h)$. Following existing literature, we use stock prices as a news shock variable because they are considered as a forward-looking variable to capture future technological developments. The error-correction representation can be written as

$$
\Delta y_{t}=\alpha \beta^{\prime} y_{t-1}+\sum_{j=1}^{p-1} \Gamma_{j} \Delta y_{t-j}+\phi D_{t}+u_{t},
$$

where $\alpha$ and $\beta$ are $K \times r$ matrices of loading coefficients and co-integrating vectors, respectively; $\Gamma_{j}$ is $K \times K$ matrix for the lags; $D_{t}$ is a deterministic term; and $u_{t}$ is the reduced from error term. In line with the literature, we can consider $u_{t}=B \varepsilon_{t}$ where $B$ is a nonsingular matrix and $\varepsilon_{t}$ is the structural shocks whose covariance matrix is an identity matrix $I_{K}$. From Johansen's version of Granger's Representation Theorem, $y_{t}$ can be represented as the following moving average form:

$$
y_{t}=L \sum_{i=1}^{t-1} \varepsilon_{i}+\sum_{i=0}^{\infty} \Xi_{i}^{*}\left(u_{t-i}+\phi D_{t-i}\right)+y_{0}^{*},
$$

where $y_{0}^{*}$ is a vector of initial variables;

$$
L \equiv \beta_{\perp}\left[\alpha_{\perp}^{\prime}\left(I_{K}-\sum_{i=1}^{p-1} \Gamma_{i}\right) \beta_{\perp}\right]^{-1} \alpha_{\perp}^{\prime}
$$

is a $K \times K$ matrix with rank $K-r ; \alpha_{\perp}$ and $\beta_{\perp}$ respectively denote the orthogonal complements of $\alpha$ and $\beta$; and the matrices $\Xi_{i}^{*}, i=1, \cdots, \infty$, are absolutely summable. $L$ is the matrix that represents the long-run effects of forecast error impulse responses.

\subsection{Identification}

$L$ can be interpreted as a long-run multiplier matrix of the structural shocks $\varepsilon_{t}$, whereas $B$ is the corresponding impact matrix. Identification requires $K(K-1) / 2$ restrictions on $B$ and $L$. The three-variable system requires three restrictions for just-identification.

We identify news shocks on the basis of previous literature. We assume that only surprise TFP shocks can have an impact effect on $t f p$. News shocks are assumed to be orthogonal to the measure of TFP on impact. The difference between news shocks and demand shocks lies in the long-run assumption. We assume that news shocks have the potential to permanently change the future TFP, while demand shocks are identified as all kinds of shocks that are orthogonal to TFP in the long run. Three restrictions are imposed under these assumptions which are summarized in Table 1.

\section{Data}

We use three variables to identify three structural shocks in the benchmark case. Japanese data for measured TFP, 
stock prices, and macro activities is taken from Ko and Miyazawa (2010). The measured TFP for the U.S. was taken from Beaudry and Lucke (2009). We employ quarterly data from 1960Q1 to 2002Q2. All variables are seasonally adjusted, in logged forms, and in per capita.

A constant is included as a deterministic term. The Akaike information criterion (AIC) reveals that three lags in levels are recommended. Johansen tests find one co-integrating vector; this result is consistent with that of Ko and Miyazawa (2010), who used a four-variable model.

\section{Main Result}

Figure 1 displays the impulse responses (IR). The variables are ordered as $t f p, s p$, and $h$ in each row. Responses to surprise TFP shocks, news shocks, and demand shocks are listed from the left to the right panels. The first column shows IRs to the surprise TFP shocks. The measured TFP permanently increases with positive stock prices. The response of hours worked in the third row shows a negative sign, which is consistent with the New Keynesian theory. The second column depicts IRs to news shocks. After the stock market innovation, the response of $t f p$ displays small fluctuations in the short run, and then, starts to increase around 12 quarters later. The response of hours worked is positive, which reflects the boom before the realization of TFP. These findings are consistent with the previous news-shock-business-cycle literature. The demand shocks increases the hours worked by definition, while the effect on tfp is insignificant.

Figure 2 shows the forecast error variance decomposition (FEVD). From FEVD, we can observe the relative contribution of each shock. Surprise TFP shocks explain more than 90 percent of the $t f p$ movements until 30 periods ahead. However, more importantly, the contribution of news shocks to the $t f p$ variance increases sharply throughout the periods. The fractions of $t f p$ movements explained by news shocks are 10 percent 35 periods later, and 25 percent 50 periods later. The contribution in the long run, that is, 200 periods later, reaches around 80 percent.

For a robustness check, we re-estimate the model with other macro activities such as output, investment, and consumption. We have not display these results, but the estimated FEVDs of $t f p$ and corresponding macro activities show almost the same shape. In all cases, it is observed that the contribution of news shocks on $t f p$ is increasing. Furthermore, news shocks play an important role in explaining macroeconomic fluctuations.

\section{The Role of the U.S. TFP as the Source of the Japanese News Shocks}

In the former section, we find that the news shocks explain a substantial fraction of the Japanese macroeconomic fluctuations. In this section, we investigate whether the technology process in the U.S. can be the source of news shocks in Japan.

\subsection{U.S. TFP}

Parente and Prescott (1994) find that a lowering of the barriers of technology adoption after World War II helped Japan establish its development miracle. More recently, Braun, Okada, and Sudo (2008) find that movements in Japanese TFP are associated with prior movements in U.S. R\&D expenditure. In this section, therefore, we investigate the technological diffusion effect in the post-war Japanese economy, taking the U.S. TFP shock as another candidate to explain the news shock in Japan.

\subsection{Co-integration of Japanese TFP and U.S. TFP}

We start by testing the hypothesis that there is no co-integrating relationship between Japanese TFP and U.S. TFP. Rejection of this hypothesis would imply that the two time series are co-integrated. We perform Johansen's trace tests for co-integration. The results are shown in Table 2. The Johansen test rejects the null hypothesis of zero co-integrating vectors at a confidence level of 99 percent. In other words, Japanese TFP and U.S. TFP are driven by a single stochastic trend.

\subsection{Main Results}

To find the role of U.S. TFP, we include measured U.S. TFP in our SVECM estimation system. The dependent variables are ordered as follows: measured Japanese TFP, an index of stock prices, measured U.S. TFP ( $\left.t f p_{-} U S\right)$, and hours worked. Table 3 reports our restrictions to identify four structural shocks. Three lags are recommended by the AIC. We find one co-integration by Johansen tests. The first and second shocks are surprise TFP shocks and news shocks. Surprise TFP shocks in Japan are identified to be exogenous on impact. News shocks identified are those that are believed to be orthogonal to measures of TFP in both countries on impact. We open the possibility that the news shocks may influence U.S. TFP as well as Japanese TFP. We put slightly severe restrictions on the third shocks. It is assumed that the U.S. technology innovation cannot influence Japanese TFP within three months. Our alternative assumption is that surprise TFP shocks in Japan have no impact effect on U.S. TFP. We estimate the model with this alternative assumption in the robustness check. Demand shocks are assumed to have no effect on technology processes. 
Figure 3 displays IRs under the four-variable system. IRs to the surprise TFP shocks, news shocks, and demands shocks are almost the same as the benchmark case. Our estimated news shocks in this section start to increase Japanese TFP 12 quarters after the stock market innovation. Furthermore, after the stock market innovation, the U.S. TFP also starts to increase around 24 quarters later, although the effect is insignificant. On the other hand, U.S. TFP shocks seem to have a permanent effect on Japanese TFP. However, there is a lag in the diffusion process. It takes around three to four quarters to increase the Japanese TFP, which reflects the international technology diffusion from the U.S. to Japan. In this respect, U.S. TFP shocks looks like news-type shocks to the Japanese economy.

Figure 4 depicts FEVDs under the four-variable system. In the $t f p$ case, the short-run movements are explained by the surprise TFP shocks in Japan. However, the contribution of the U.S. TFP shocks becomes dominant in the medium and the long run, explaining more than 70 percent of the movements 50 quarters later. The second and the third panels show that most of the movements of Japanese stock prices and U.S. TFP are respectively explained by news shocks and U.S. TFP shocks. The contribution of each shock to hours worked is displayed in the fourth panel. The contribution of the U.S. TFP shocks is observed to be considerable.

\subsection{Robustness Check}

\subsubsection{Other macro activities}

As a robustness check, we re-estimate the model with different macro activities instead of hours worked. Two lags were recommended for output and consumption, and three lags for investment by AIC. In all the cases, one co-integrating vector was found by the Johansen tests. Figure 5 displays FEVDs of Japanese TFP and macro activities. FEVDs of output, investment, and consumption are displayed in descending order. In all the cases, the estimated U.S. TFP shocks explain a substantial fraction of the medium- and long-run TFP movement in Japan in the left column. In particular, the contribution is considerable in the investment case. The contribution of U.S. TFP shocks on macro activities is also sizable. Therefore, we conclude that news shocks are important in explaining Japanese macroeconomic fluctuations but many elements of the news shocks originate from the U.S. TFP.

\subsubsection{Alternative identification scheme}

We impose slightly more restrictions on the U.S. TFP shocks. Therefore, we consider the opposite case imposing more restrictions on the Japanese TFP shocks. Table 3 reports the alternative restrictions. We also perform many robustness checks with possible restriction schemes and find that the estimated results were almost the same as in the former case.

\subsubsection{U.S. stock prices and U.S. TFP news shocks}

Estimated news shocks on Japanese TFP turn out to have an insignificant effect on the U.S. TFP. Moreover, by construction, the estimated third shock is a surprise shock because the U.S. TFP increases on impact. However, as Beaudry and Portier (2006) and Beaudry and Lucke (2009) emphasize, TFP news shocks in the U.S. are the driving source in the U.S. macroeonomy. Therefore, we investigate the role of the U.S. TFP news shocks on the Japanese economy. To identify the U.S. news shocks, we use the Standard \& Poors 500 index (SP 500) in per capita. The order of dependent variables is as follows: measured U.S. TFP, SP 500, measured Japanese TFP, and Japanese macro activity such as hours worked and output. The identification scheme is the same as the benchmark case and reported in Table 5. Notice that we put equal restrictions on two surprise shocks.

The estimated news shocks start to increase measured U.S. TFP around four to five quarters after the U.S. stock market innovation. Japanese TFP also starts to increase eight to nine quarters later. Observed impulse response implies that it takes one year for the U.S. technology to be transferred to Japan. The contribution of U.S. TFP news shocks is listed in Table 6. In all cases, the contribution of U.S. news shocks on measured U.S. TFP is strictly increasing as time goes by. This finding is consistent with Beaudry and Lucke (2009). More importantly, their contribution to Japanese TFP is also increasing. Consequently, the effect on Japanese macro activities is substantial especially in the long run. We do not list consumption because we did not get the proper results on IRs.

\section{Conclusion}

What is the source of Japanese business cycle fluctuations? We answer this fundamental question from the perspective of the SVECM approach, in line with Beaudry and Portier (2005) and Beaudry and Lucke (2009). In the benchmark case, we came up with the same key finding as Ko and Miyazawa (2010): technology shocks are important to explain the variance of macro activities, but many parts are anticipated.

We investigate the role of U.S. TFP on Japanese macroeconomic fluctuations in two ways. We adopt the measured U.S. TFP as an alternative candidate of the driving force. The order of dependent variables is as follows: measured TFP in Japan, Japanese stock prices, measured TFP in the U.S., and Japanese macro activities. Our main findings are as follows. First, the estimated news shocks in Japan start to increase Japanese TFP three years later. After the Japanese stock market innovation, U.S. TFP lags Japanese TFP, although the effect is statistically insignificant. On 
the other hand, U.S. TFP innovation significantly increases Japanese TFP four quarters later. Second, the forecast error variance decomposition shows that a considerable fraction of Japanese TFP in the medium and long run is explained by the U.S. TFP shocks. However, the contribution of both of surprise and news shocks in Japan is negligible to explain the movements of U.S. TFP. Third, the role of news shocks captured by the Japanese stock market innovations, which rarely have information of U.S. TFP in the four-variable system, becomes limited. Fourth, surprise TFP shocks in Japan can explain the short-run movement of Japanese TFP but have little effect on U.S. TFP.

As an alternative approach, we use both U.S. TFP and U.S. stock prices. The order of dependent variables is: measured TFP in the U.S., U.S. stock prices, measured TFP in Japan, and Japanese macro activities. Our estimated news shocks in the U.S. start to increase U.S. TFP around one year later, and then increases Japanese TFP two years later. News shocks on U.S. TFP explain substantial parts of Japanese TFP and macro activities especially in the long run.

\section{References}

Beaudry, P., \& Lucke, B. (2009). Letting Different Views about Business Cycles Complete. NBER Macroeconomics Annual, 2009.

Beaudry, P., \& Portier, F. (2005). The "News View" of Economic Fluctuations: Evidence from Aggregate Japanese Data and Sectoral US Data. Journal of the Japanese and International Economics, 19, 635-652. http://dx.doi.org/10.1016/j.jjie.2005.10.004

Beaudry, P., \& Portier, F. (2006). Stock Prices, News and Economic Fluctuations. American Economic Review, 96, 1293-1307. http://dx.doi.org/10.1257/aer.96.4.1293

Braun R. A., Okada, T., \& Sudo, N. (2008). U.S. R\&D and Japanese Medium Term Cycles. Bank of Japan Working Paper Series, No. 06-E-06.

Braun, R. A., \& Shioji, E. (2007). Investment Specific Technological Changes in Japan. Seoul Journal of Economics 20 (1), 165-200.

Eaton, J., \& Kortum, S. (1997). Engines of Growth: Domestic and Foreign Sources of Innovation. Japan and the World Economy, 91 (2): 235-259. http://dx.doi.org/10.1016/S0922-1425(97)00011-X

Eaton, J., \& Kortum, S, (1996). Trade in Ideas: Patenting and Productivity in the OECD. Journal of International Economics, 40 (3-4): 251-278. http://dx.doi.org/10.1016/0022-1996(95)01407-1

Fujiwara, I., Hirose Y., \& Shintani M. (2011). Can News Be a Major Source of Aggregate Fluctuations? A Bayesian DSGE Approach. Journal of Money, Credit and Banking, 43 (1). http://dx.doi.org/10.1111/j.1538-4616.2010.00363.x

Johansen, S. (1996). Likelihood Based Inference in Cointegrated Vector Autoregressive Models. 2nd edition. Oxford University Press, Oxford.

Ko, J. H., \& Miyazawa K., (2010) News Shocks and the Japanese Macroeconomic Fluctuations. Research Center for Price Dynamics Working Paper Series No. 52.

Lutkepohl, H. (2005). New Introduction to Multiple Time Series Analysis, Springer Verlag Berlin.

Parente, S., \& Prescott, E. (2004). A Unified Theory of the Evolution of International Income Levels. Federal Reserve Bank of Minneapolis Staff Report 333.

Parente, S., \& Prescott, E. (1994). Barriers to Technology Adoption and Development. Journal of Political Economy, 102 (2): 298-321. http://dx.doi.org/10.1086/261933

Table 1. B matrix and L matrix

\begin{tabular}{|c|c|c|c|}
\hline \multicolumn{4}{|c|}{ B matrix } \\
\hline & $\begin{array}{c}\text { Surprise } \\
\text { TFP shock }\end{array}$ & News shock & $\begin{array}{c}\text { Demand } \\
\text { shock }\end{array}$ \\
\hline$t f p$ & $*$ & 0 & 0 \\
\hline$s p$ & $*$ & $*$ & $*$ \\
\hline$h$ & $*$ & $*$ & $*$ \\
\hline
\end{tabular}

\begin{tabular}{|c|c|c|c|}
\hline \multicolumn{4}{|c|}{ L matrix } \\
\hline & $\begin{array}{c}\text { Surprise } \\
\text { TFP shock }\end{array}$ & News shock & $\begin{array}{c}\text { Demand } \\
\text { shock }\end{array}$ \\
\hline$t f p$ & $*$ & $*$ & 0 \\
\hline$s p$ & $*$ & $*$ & $*$ \\
\hline$h$ & $*$ & $*$ & $*$ \\
\hline
\end{tabular}

Dependent variables are listed in rows and structural shocks are listed in columns. Starred entries mean that the corresponding elements are not restricted. Zero entries indicate that the corresponding shocks have no effect on the corresponding variables. 
Table 2. Johansen trace test for cointegration

\begin{tabular}{|c|c|c|c|c|c|}
\hline Null hypothesis & Likelihood ratio & p value & $90 \%$ & $95 \%$ & $99 \%$ \\
\hline$r=0$ & 33.53 & 0.0003 & 17.98 & 20.16 & 24.69 \\
\hline
\end{tabular}

The variable $r$ denotes the number of cointegrating vectors. Akaike information criterion shows that three lags are recommended.

Table 3. $B$ matrix and $L$ matrix

\begin{tabular}{|c|c|c|c|c|}
\hline \multicolumn{5}{|c|}{$B$ matrix } \\
\hline & $\begin{array}{c}\text { Surprise } \\
\text { TFP shock }\end{array}$ & $\begin{array}{c}\text { News } \\
\text { shock }\end{array}$ & $\begin{array}{c}\text { U.S. TFP } \\
\text { shock }\end{array}$ & $\begin{array}{c}\text { Demand } \\
\text { shock }\end{array}$ \\
\hline$t f p$ & $*$ & 0 & 0 & 0 \\
\hline$s p$ & $*$ & $*$ & $*$ & $*$ \\
\hline$t f p \_U S$ & $*$ & 0 & $*$ & $*$ \\
\hline$h$ & $*$ & $*$ & $*$ & $*$ \\
\hline
\end{tabular}

\begin{tabular}{|c|c|c|c|c|}
\hline \multicolumn{5}{|c|}{ L matrix } \\
\hline & $\begin{array}{c}\text { Surprise } \\
\text { TFP shock }\end{array}$ & $\begin{array}{c}\text { News } \\
\text { shock }\end{array}$ & $\begin{array}{c}\text { U.S. TFP } \\
\text { shock }\end{array}$ & $\begin{array}{c}\text { Demand } \\
\text { shock }\end{array}$ \\
\hline$t f p$ & $*$ & $*$ & $*$ & 0 \\
\hline$s p$ & $*$ & $*$ & $*$ & 0 \\
\hline$t f p \_U S$ & $*$ & $*$ & $*$ & $*$ \\
\hline$h$ & $*$ & $*$ & $*$ & $*$ \\
\hline
\end{tabular}

Dependent variables are listed in rows and structural shocks are listed in columns. Starred entries mean that the corresponding elements are not restricted. Zero entries indicate that the corresponding shocks have no effect on the corresponding variables.

Table 4. $B$ matrix and $L$ matrix

\begin{tabular}{|c|c|c|c|c|}
\hline \multicolumn{5}{|c|}{$B$ matrix } \\
\hline & $\begin{array}{c}\text { Surprise } \\
\text { TFP } \\
\text { shock }\end{array}$ & $\begin{array}{c}\text { News } \\
\text { shock }\end{array}$ & $\begin{array}{c}\text { U.S. } \\
\text { TFP } \\
\text { shock }\end{array}$ & $\begin{array}{c}\text { Demand } \\
\text { shock }\end{array}$ \\
\hline$t f p$ & $*$ & $*$ & 0 & 0 \\
\hline$s p$ & $*$ & $*$ & $*$ & $*$ \\
\hline$t f p \_U S$ & 0 & 0 & $*$ & $*$ \\
\hline$h$ & $*$ & $*$ & $*$ & $*$ \\
\hline
\end{tabular}

\begin{tabular}{|c|c|c|c|c|}
\hline \multicolumn{5}{|c|}{ L matrix } \\
\hline & $\begin{array}{c}\text { Surprise } \\
\text { TFP } \\
\text { shock }\end{array}$ & $\begin{array}{c}\text { News } \\
\text { shock }\end{array}$ & $\begin{array}{c}\text { U.S. } \\
\text { TFP } \\
\text { shock }\end{array}$ & Demand shock \\
\hline$t f p$ & $*$ & $*$ & $*$ & 0 \\
\hline$s p$ & $*$ & $*$ & $*$ & 0 \\
\hline$t f p \_U S$ & $*$ & $*$ & $*$ & $*$ \\
\hline$h$ & $*$ & $*$ & $*$ & $*$ \\
\hline
\end{tabular}

Dependent variables are listed in rows and structural shocks are listed in columns. Starred entries mean that the corresponding elements are not restricted. Zero entries indicate that the corresponding shocks have no effect on the corresponding variables.

Table 5. $B$ matrix and $L$ matrix

\begin{tabular}{|c|c|c|c|c|}
\hline \multicolumn{5}{|c|}{ B matrix } \\
& Surprise & U.S. & Jap. & Demand \\
& U.S. TFP & News & TFP & shock \\
& shock & shock & shock & \\
\hline$t f p \_U S$ & $*$ & 0 & 0 & 0 \\
\hline$s p \_U S$ & $*$ & $*$ & $*$ & $*$ \\
\hline$t f p$ & 0 & 0 & $*$ & $*$ \\
\hline$h$ & $*$ & $*$ & $*$ & $*$ \\
\hline
\end{tabular}

\begin{tabular}{|c|c|c|c|c|}
\hline \multicolumn{5}{|c|}{ L matrix } \\
\hline & $\begin{array}{c}\text { Surprise } \\
\text { U.S. TFP } \\
\text { shock }\end{array}$ & $\begin{array}{c}\text { U.S. } \\
\text { News } \\
\text { shock }\end{array}$ & $\begin{array}{c}\text { Jap. TFP } \\
\text { shock }\end{array}$ & $\begin{array}{c}\text { Demand } \\
\text { shock }\end{array}$ \\
\hline$t f p$ & $*$ & $*$ & $*$ & 0 \\
\hline$s p$ & $*$ & $*$ & $*$ & $*$ \\
\hline$t f p \_U S$ & $*$ & $*$ & $*$ & 0 \\
\hline$h$ & $*$ & $*$ & $*$ & $*$ \\
\hline
\end{tabular}

Dependent variables are listed in rows and structural shocks are listed in columns. Starred entries mean that the corresponding elements are not restricted. Zero entries indicate that the corresponding shocks have no effect on the corresponding variables.

Table 6. Contribution of U.S. TFP news shocks

\begin{tabular}{|c|c|c|c|c|}
\hline \multicolumn{5}{|c|}{$h$ system } \\
\hline & 10 period & 50 period & 100 period & 200 period \\
\hline$t f p \_U S$ & 0 & 30 & 57 & 74 \\
\hline$s p \_U S$ & 84 & 84 & 85 & 85 \\
\hline$t f p$ & 1 & 31 & 61 & 78 \\
\hline$h$ & 19 & 17 & 49 & 72 \\
\hline
\end{tabular}

\begin{tabular}{|c|c|c|c|c|}
\hline \multicolumn{5}{|c|}{$\mathrm{y}$ system } \\
\hline & 10 period & 50 period & 100 period & 200 period \\
\hline$t f p \_U S$ & 1 & 42 & 55 & 59 \\
\hline$s p \_U S$ & 18 & 14 & 12 & 11 \\
\hline$t f p$ & 10 & 83 & 86 & 87 \\
\hline$y$ & 77 & 89 & 90 & 91 \\
\hline
\end{tabular}

\begin{tabular}{|c|c|c|c|c|}
\hline \multicolumn{7}{|c|}{ isystem } & 200 period \\
\hline & 10 period & 50 period & 100 period & 40 \\
\hline$t f p \_U S$ & 0 & 26 & 35 & 1 \\
\hline$s p \_U S$ & 9 & 3 & 2 & 64 \\
\hline$t f p$ & 4 & 57 & 63 & 90 \\
\hline$i$ & 90 & 91 & 91 & \\
\hline
\end{tabular}

FEVDs with different macro activities are reported in each table. Values in each entry explain the contribution of U.S. TFP news shocks. $t f p \_U S$ denotes measured U.S. TFP. $s p \_U S$ denotes SP 500. We do not show the results with consumption because we could not get proper IRs. 

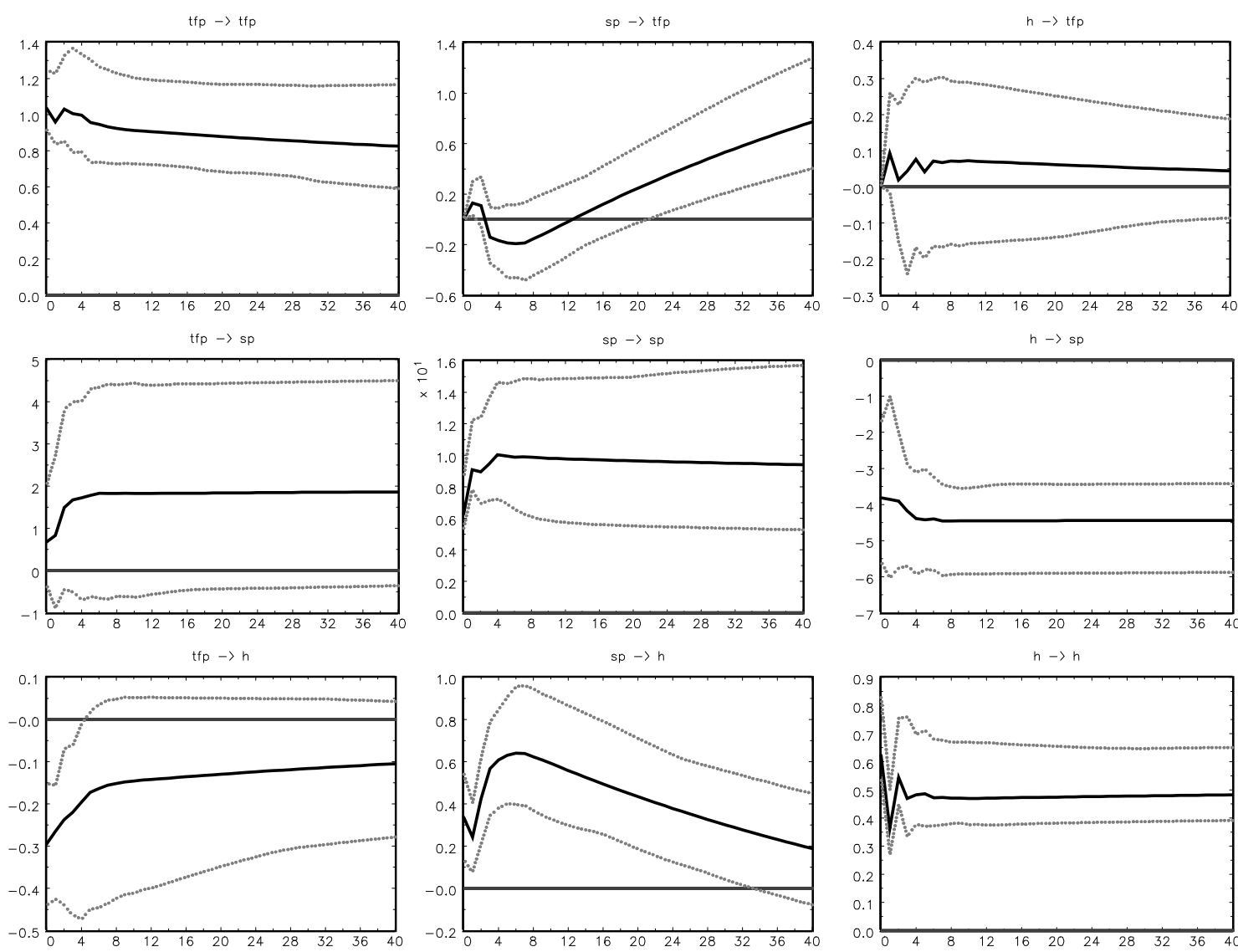

Figure 1. IRs with three-variable case

Impulses are given in columns, responding variables in rows. Solid lines represent the estimated impulse responses to each shock, and dashed lines are two standard errors bootstrapped confidence intervals (Hall).
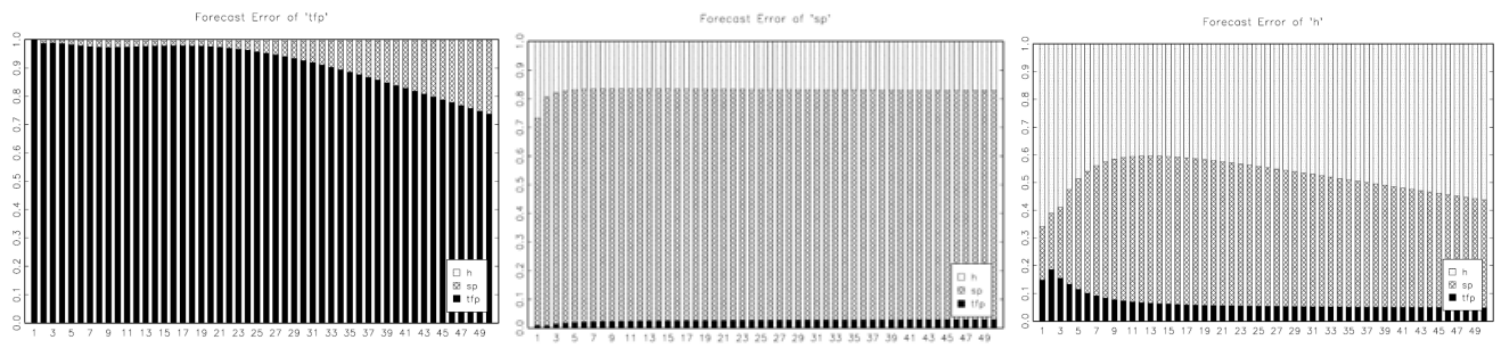

Figure 2. FEVDs with the three-variable case

FEVDs of $t f p, s p$, and $h$ are listed from the left to the right panels. The darkest solid bars represent the contribution of surprise TFP shocks. Diagonal cross-hatch bars represent the share of news shocks. The lightest dotted bars represent the contribution of demand shocks. 

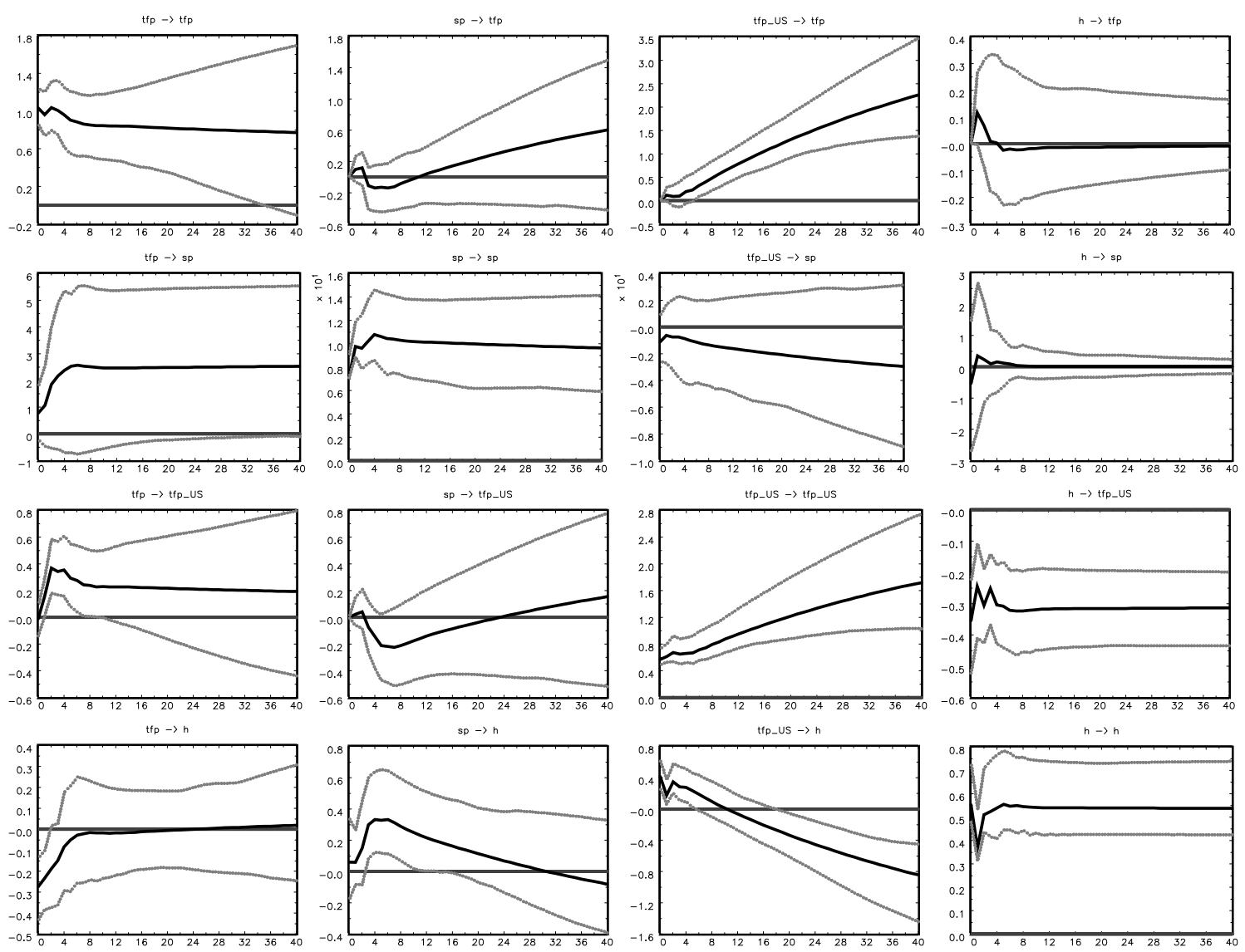

Figure 3. IRs with the four-variable case

Impulses are given in columns, responding variables in rows. Solid lines represent the estimated impulse responses to each shock, and dashed lines are two standard errors bootstrapped confidence intervals (Hall). 

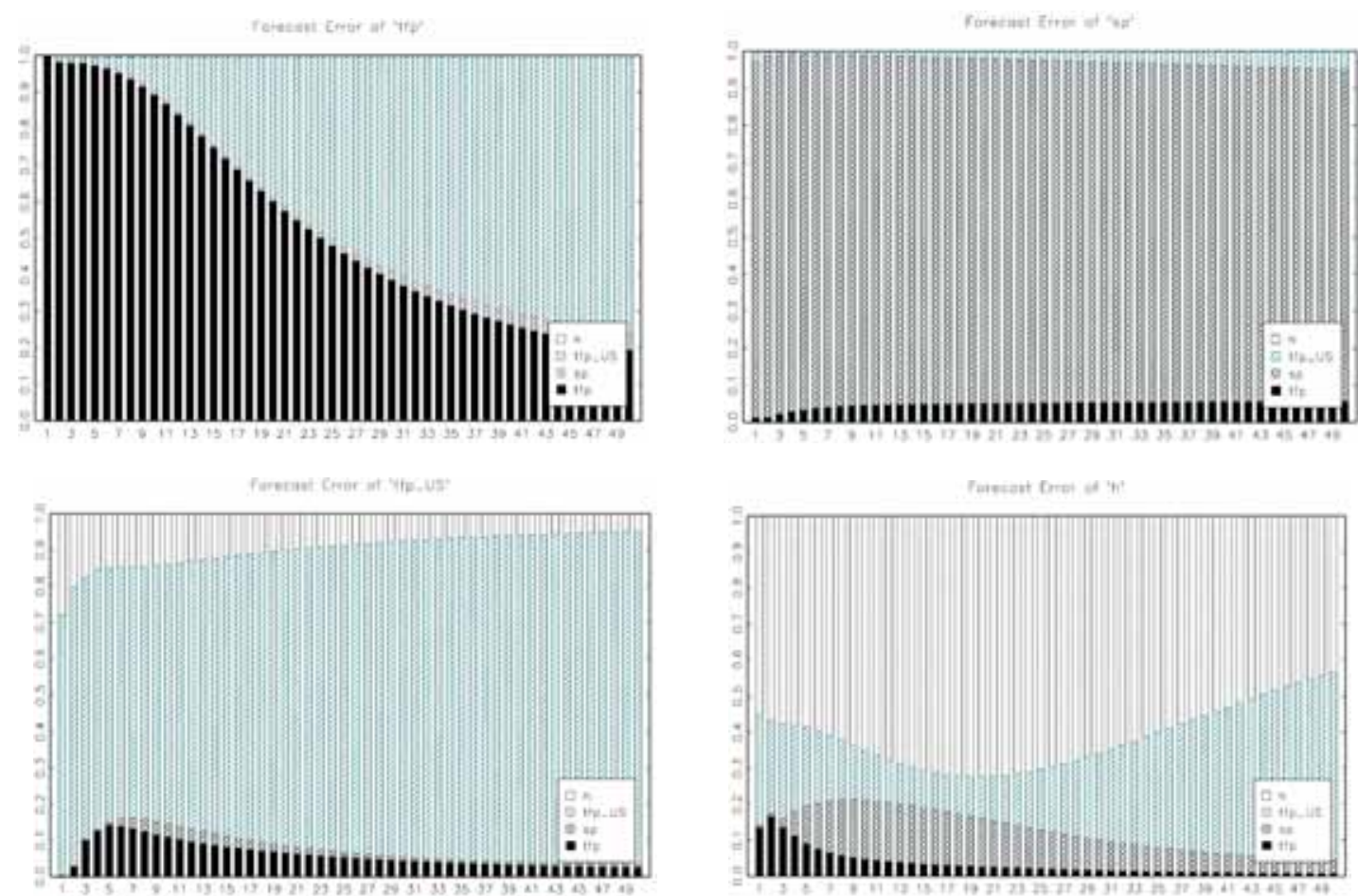

Figure 4. FEVDs with the four-variable case

FEVDs of $t f p$, $s p$, and $h$ are listed from the left to the right panels. The darkest solid bars represent the contribution of surprise TFP shocks. Diagonal cross-hatch bars represent the contribution of news shocks. Bars with diagonal lines with negative slope represent the contribution of U.S. TFP shocks. The lightest dotted bars represent the contribution of demand shocks. 

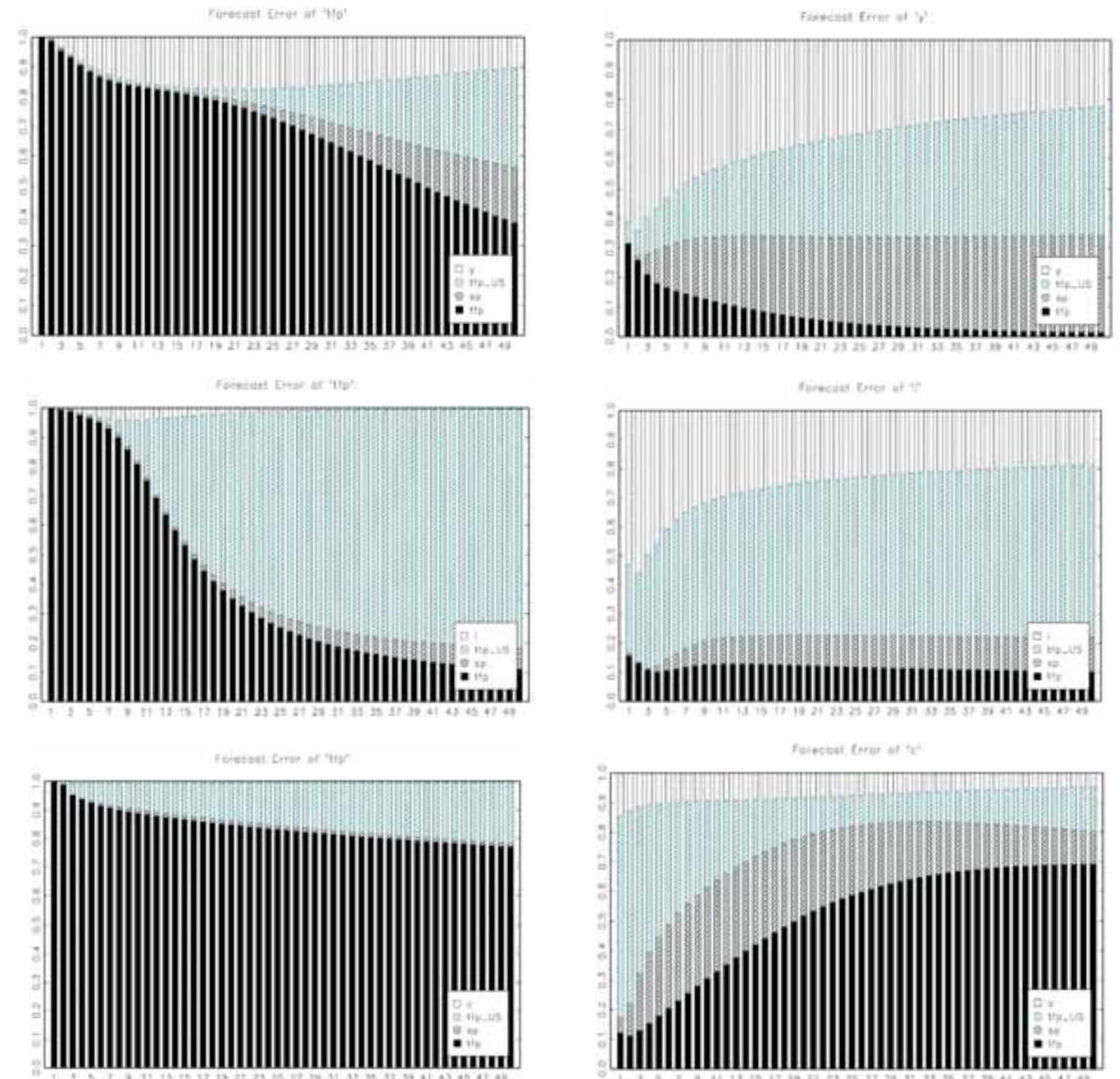

Figure 5. FEVDs with different macro activities

FEVDs of $t f p$ are listed in the left column. FEVDs of other macro activities are in the right column. The darkest solid bars represent the contribution of surprise TFP shocks. Diagonal cross-hatch bars represent the contribution of news shocks. Bars with diagonal lines with negative slope represent the contribution of U.S. TFP shocks. The lightest dotted bars represent the contribution of demand shocks. 